\title{
Adição de betaína ao diluente leite em pó desnatado durante a conservação do sêmen do varrão a $10^{\circ} \mathrm{C}$ *
}

\section{The Betaine additionin skimed milk powder extender during boar semen storage at $10^{\circ} \mathrm{C}$}

\author{
Lina Raquel Santos Araújo, ${ }^{* *}$ Aline Viana Dias, ${ }^{* *}$ Tatyane Bandeira Barros, ${ }^{* *}$ Daianny Barboza Guimarães, ${ }^{* *}$ \\ Ludymila Furtado Cantanhêde, ${ }^{* *}$ Ricardo Toniolli**
}

\begin{abstract}
Resumo
A betaína é um constituinte do plasma seminal humano, cuja baixa concentração tem sido relacionada à infertilidade, entretanto não há relatos sobre seus efeitos no sêmen suíno. O presente estudo teve como objetivo verificar os efeitos da adição de diferentes concentrações de betaína sobre espermatozoides suínos diluídos e conservados em leite em pó desnatado a $10^{\circ} \mathrm{C}$ por quatro dias. Foram analisados 56 ejaculados submetidos a quatro tratamentos: 1. Leite em pó desnatado (LPD); 2. LPD+1g betaína/100mL; 3. $\mathrm{LPD}+2 \mathrm{~g}$ betaína/100mL e 4 . LPD $+3 \mathrm{~g}$ betaína/100mL. Foram realizadas análises diárias (D0-D4) de vigor e motilidade e no D0 e D4 foi realizado o teste hiposmótico e esfregaço para avaliar a vitalidade e integridade acrossomal. Os resultados de vigor, motilidade e vitalidade espermática diferiram entre os tratamentos, sendo superior no $\mathrm{T} 1(\mathrm{p}<0,05)$. que também manteve o maior percentual de células com membrana íntegra em D0 e em D4, porém, neste último não diferiu $(P>0,05)$ de $T 4$. A betaína não exerceu efeito protetor sobre a célula espermática suína diluída e conservada em meio à base de LPD a $10^{\circ} \mathrm{C}$. A adição de concentrações iguais ou acima de $1 \mathrm{~g}$ de betaína no diluente influenciaram negativamente a qualidade do sêmen, portanto, não são aplicáveis na conservação do sêmen suíno resfriado $a 10^{\circ} \mathrm{C}$ em LPD.
\end{abstract}

Palavras-chave: trimetilglicina, diluente alternativo, ejaculado.

\begin{abstract}
Betaine is a constituent of human seminal plasma, and low concentrations have been linked to infertility, however there are no reports about its effects on boar semen. The aim of this study was to determine the effects of adding different concentrations of betaine on boar spermatozoa diluted and stored in skimmed milk powder (SMP) at $10{ }^{\circ} \mathrm{C}$. Un total of 56 ejaculates were analyzed, being subjected to four treatments: 1 . SMP; 2 . SMP+1g betaine/100mL; 3. SMP+2g betaine/100mL; and 4. SMP+3g betaine/100mL. Analyzes of vigor and sperm motility were performed daily (D0-D4) and, at D0 and D4, the hiposmotic test and the smear were performed for evaluation of vitality and acrosomal integrity. The results of vigor, vitality and sperm motility differed between treatments, being higher in T1 $(p<0,05)$. The T1 also maintained the highest percentage of cells with intact membrane at D0 and D4, However, the latter did not differ statistically from T4 $(P>0,05)$. Betaine did not exert a protective effect on boar sperm cell when diluted and preserved in SMP diluent at $10^{\circ} \mathrm{C}$. Adding concentrations equal to or greater than $1 \mathrm{~g}$ of betaine in the extender negatively affected the quality of semen; therefore, these concentrations are not applicable in the preservation of boar semen cooled to $10{ }^{\circ} \mathrm{C}$ in $\mathrm{SMP}$.
\end{abstract}

Keywords: trimethylglycine, alternative diluent, sperm.

\section{Introdução}

A Glicina betaína ou betaína, é um derivado trimetil do aminoácido glicina (N,N,N-trimetilglicina), que desempenha um importante papel na manutenção do equilíbrio osmótico (Eklund et al., 2005) e tem sido utilizada como crioprotetor (Lindeberg et al., 1999). Foi demonstrado que ela melhora a qualidade e viabilidade dos espermatozoides criopreservados de carneiro (Sanchez-Partida et al., 1992), de caninos (Peña et al., 1998), de equinos (Trimeche et al.,1999; Junnila, 2000) e de bovinos (Zhang et al., 2001) entretanto não há relatos sobre seus efeitos no sêmen suíno.
A betaína é um constituinte do plasma seminal no homem, onde baixas concentrações desta molécula têm sido relacionadas a problemas de infertilidade (Johnson et al., 2012). Por ser uma molécula eletricamente carregada, pode interagir eletrostaticamente com grupos fosfato dos fosfolipídios da membrana plasmática do espermatozoide, formando assim uma camada na superfície da célula, protegendo-a contra o choque térmico (El-Sheshtawy et al., 2008).

O sêmen suíno difere em vários aspectos do sêmen de outros animais domésticos, sendo produzido em grande volume mais vulnerável ao choque térmico após sua coleta (Johnson et al.,

\footnotetext{
*Recebido em 28 de outubro de 2013 e aceito em 13 de janeiro de 2014.

**Universidade Estadual do Ceará. E-mail para contato: toniolli@roadnet.com.br.
} 
2000). Desta forma, o processamento do sêmen utilizando diluentes adequados é um dos pontos importantes para sua conservação e consequentemente para o sucesso de um programa de inseminação artificial (Ochoa e Ortega, 2008). $\mathrm{O}$ diluente possui várias funções, tais como, aumentar $\mathrm{o}$ volume do ejaculado, fornecer nutrientes para a produção de energia, proteger os espermatozoides contra o choque térmico, controlar a variação de $\mathrm{pH}$, manter o balanço osmótico e inibir o desenvolvimento bacteriano (Johnson et al., 2000; Ochoa e Ortega, 2008).

Numerosos trabalhos têm sido efetuados com a finalidade de desenvolver um diluente para diferentes machos domésticos. Dentre os diluentes alternativos, o leite em pó desnatado tem se mostrado como um bom conservador do espermatozoide, especialmente em baixas temperaturas (Meirelles et al., 1998). O presente estudo teve como objetivo verificar os efeitos da adição de diferentes concentrações de betaína sobre espermatozoides do varrão diluídos e conservados em leite em pó desnatado a $10^{\circ} \mathrm{C}$.

\section{Material e métodos}

O presente estudo atende aos critérios solicitados pela CEUAUECE, cujo projeto de pesquisa (processo $n^{\circ} 11223066-0 / 48$ ) foi aprovado pelo Comitê de Ética da Universidade Estadual do Ceará, em 29 de setembro de 2011.

Foi utilizado ejaculado de sete reprodutores suínos mantidos em sistema rotineiro de coletas. Os animais foram coletados uma vez por semana durante nove semanas $(n=63)$, por meio da técnica da mão enluvada e o sêmen coletado em recipiente coberto por filtro e protegido por copo térmico. Foi aproveitado o ejaculado total após a separação da parte gelatinosa retida em filtro. Foram utilizados animais com idade variando entre $12 \mathrm{e}$ 36 meses. Os animais eram alojados em baias individuais, com água à vontade disponibilizada em bebedouros tipo chupeta $\mathrm{e}$ alimentados uma vez ao dia com $2,5 \mathrm{Kg}$ de ração de reprodução.

A qualidade do ejaculado in natura foi avaliada pelas seguintes características: concentração espermática $\left(\times 10^{6} \mathrm{sptz} / \mathrm{mL}\right)$, volume $(\mathrm{mL})$, total de espermatozoides (x109 sptz), vigor espermático $(0$ a 5) (Toniolli, 1996) e porcentagem de células móveis (valores de 0 a $100 \%$ ). Apenas os ejaculados que apresentaram vigor $\geq$ 3,5 e motilidade $\geq 85 \%$, foram utilizados.

Foi separado de cada ejaculado um total de $2,1 \times 10^{9} \mathrm{sptz}$, distribuídos entre quatro tratamentos a uma concentração de $35 \times 10^{6} \mathrm{sptz} / \mathrm{mL}$, com um volume final por tratamento de $15 \mathrm{~mL}$ (sêmen+diluente) por tratamento. Este volume foi repartido em cinco tubos de ensaio por tratamento $\left(3 \mathrm{~mL}=105 \times 10^{6} \mathrm{sptz} /\right.$ tubo). O dia da coleta foi considerado dia zero (D0), e o sêmen foi conservado até quatro dias após a coleta (D4), com análises diárias no D0, D1, D2, D3 e D4. O meio de diluição/conservação testado foi o leite em pó desnatado (LPD) preparado em água destilada na seguinte proporção: $10 \mathrm{~g}$ de LPD + 0,194g glicose (Dinâmica $\left.{ }^{\circledR}\right)+100 \mathrm{~mL}$ de água destilada + sulfato de gentamicina (Virbac®) a $80 \mathrm{mg} / 100 \mathrm{~mL}$. A composição do leite desnatado encontra-se na Tabela 1.

Os tratamentos experimentais foram: 1) LPD sem betaína como tratamento controle (T1); 2) LPD $+1 \mathrm{~g}$ de betaína/100mL (1\%) (T2); 3) LPD + $2 \mathrm{~g}$ de betaína/100mL(2\%) (T3) e 4) LPD + 3g de betaína/100mL(3\%) (T4). O sêmen diluído foi submetido a um período de conservação de 4 dias à temperatura de $10^{\circ} \mathrm{C}$.
Os diluentes dos referidos tratamentos foram preparados no dia da coleta, antes do início dos trabalhos. Após a coleta e análise de cada animal, foram retiradas amostras de sêmen puro (4) e colocadas em banho-maria a $30^{\circ} \mathrm{C}$ por 10 minutos. Após esse tempo, cada amostra de sêmen in natura foi acrescida do respectivo diluente $\left(\mathrm{a} 30^{\circ} \mathrm{C}\right)$ correspondente a cada tratamento, até atingir o volume de $15 \mathrm{~mL}$. Esse volume foi fracionado em cinco tubos, sendo que cada um correspondia a um dia de análise. As amostras permaneceram estocadas por 1 hora em geladeira equipada com termostato regulado em $17^{\circ} \mathrm{C}$; após esse tempo, foram transferidas para o refrigerador à temperatura de $10^{\circ} \mathrm{C}$ (temperatura de conservação).

Tabela 1: Composição do leite em pó desnatado

\begin{tabular}{lc}
\hline Composição & Quantidade em $10 \mathrm{~g}$ \\
\hline Carboidratos & $5,60 \mathrm{~g}$ \\
Proteínas & $2,08 \mathrm{~g}$ \\
Sódio & $30 \mathrm{mg}$ \\
Cálcio & $200 \mathrm{mg}$ \\
Ferro & $1,72 \mathrm{mg}$ \\
Vitamina A & $56,4 \mu \mathrm{g}$ \\
Vitamina D & $0,6 \mu \mathrm{g}$ \\
Vitamina E & $1,88 \mathrm{mg}$ \\
Vitamina C & $9,2 \mathrm{mg}$ \\
Ácido fólico & $48 \mu \mathrm{g}$ \\
\hline
\end{tabular}

O sêmen diluído foi conservado durante 4 dias (D0, D1, D2, D3 e D4). A cada dia, foram retirados os tubos de cada ejaculado/tratamento e incubados a $39^{\circ} \mathrm{C}$ por 10 minutos, para realização das análises. Foram analisadas as seguintes características: vigor espermático, porcentagem de células móveis (motilidade); morfologia acrossomal, vitalidade espermática e espermatozoides reativos ao teste hiposmótico.

Visando a avaliação da qualidade espermática, foi analisado o vigor espermático (0 a 5) (Toniolli, 1996) e a porcentagem de células móveis (motilidade - 0 a $100 \%$ ) em microscopia óptica, colocando-se uma gota de sêmen de $15 \mu \mathrm{L}$ entre lâmina e lamínula e com leitura em três campos, em aumento de 200 vezes. A análise destas características foi realizada durante todo o período de conservação (D0, D1, D2, D3 e D4).

As amostras para avaliação da morfologia acrossomal e vitalidade espermática (\% de células vivas) foram processadas visando as análises em D0 ( $\geq 6$ horas após coleta e diluição Exame 1) e no D4 (após 10 minutos de reaquecimento a $39^{\circ} \mathrm{C}$ - Exame 2), avaliando-se as duas características em uma mesma lâmina. Foram feitos esfregaços de sêmen corados, contando-se 200 células/lâmina em microscopia óptica com lente de imersão (1000x). A solução corante foi formada pelo azul de bromo-fenol $(0,1 \mathrm{~g})$, citrato de sódio $(0,4 \mathrm{~g})$, água destilada $(10 \mathrm{~mL})$. Juntou-se uma gota de sêmen com outra de corante sendo em seguida homogeneizada. Após 30 segundos, procedeu-se o esfregaço, sendo secado à temperatura ambiente. Para esta análise, os espermatozoides foram classificados em quatro categorias: 1) Vivos com acrossoma intacto; 2) Vivos com acrossoma danificado; 3) Mortos com acrossoma intacto; 4) Mortos com acrossoma danificado. 
O teste hiposmótico foi realizado nos dias D0 e D4, visando a avaliação da funcionalidade da membrana espermática, através de uma prova de resistência ao choque osmótico. A técnica consistiu da adição de $0,5 \mathrm{~mL}$ de sêmen diluído em $7,5 \mathrm{~mL}$ de água destilada, mantidos por 15 minutos em banho-maria a $39{ }^{\circ} \mathrm{C}$ (solução $\mathrm{A}$ ). Após este período de incubação, em 1 $\mathrm{mL}$ da solução $A$, foi adicionado $0,5 \mathrm{~mL}$ de formol salino a $1 \%$ (solução B). Dessa nova solução foi retirado uma alíquota de $15 \mu \mathrm{L}$, colocado em uma lâmina, recoberto por lamínula e em seguida levado ao microscópio óptico com um aumento de 400x, sendo contadas um total de 200 células. O espermatozoide com a cauda reta era indicativo de ruptura de membrana e os que permaneceram com membrana integra apresentaram diferentes níveis de enrolamento da cauda. Um sêmen de qualidade deve apresentar no mínimo $50 \%$ de espermatozoides com cauda enrolada.

O delineamento experimental utilizado foi o de blocos ao acaso, onde cada ejaculado foi considerado uma repetição $(r=63)$, sendo submetido aos 4 tratamentos. Aplicou-se o teste de Mann Whitney, para a comparação entre grupos e o Qui-quadrado, para os resultados em que se realizou contagem de células. Usou-se o Programa StatView (versão 5.0.1; SAS Institute Inc. 1992-1998) com nível de significância de 95\% ( $p<0,05)$.

\section{Resultados e discussão}

A fração espermática do sêmen in natura dos 56 ejaculados analisados no experimento apresentou aspecto normal, coloração branco leitosa, volume médio de 238 $\mathrm{mL}$ e concentração média de $437,2 \times 10^{6} \mathrm{sptz} / \mathrm{mL}$. Tais características estão dentro da normalidade para a espécie suína (Smital, 2009). O sêmen in natura apresentou uma motilidade média de $90 \pm 6,0$ e vigor de $4,3 \pm 0,3$. Devido a oscilações de temperatura durante a conservação, cinco amostras foram perdidas em D1.

O tratamento controle obteve as melhores médias de vigor espermático durante todo o período de conservação, em relação aos demais tratamentos. À medida que se aumentou a concentração da betaína adicionada ao diluente, os valores médios do vigor espermático diminuíram, sendo que na maior concentração $(3 \mathrm{~g} / 100 \mathrm{~mL})$ os valores do vigor zeraram já a partir de 24 horas de conservação (D1). Todos os tratamentos diferiram entre si $(p<0,05)$ durante o período de conservação, mas em D4, o vigor espermático das amostras com betaína a 2 e 3g/ $100 \mathrm{~mL}$ foi semelhantes (Tabela 2).

Tabela 2: Análise do vigor espermático do sêmen suíno conservado em LPD a $10^{\circ} \mathrm{C}$, com diferentes concentrações de betaína

\begin{tabular}{cccccc}
\hline \multirow{2}{*}{$\begin{array}{c}\text { Tratamentos } \\
(\mathbf{g} / \mathbf{1 0 0} \mathbf{~} \mathbf{L})\end{array}$} & D0 & D1 & D2 & D3 & D4 \\
\cline { 2 - 6 } & $3,1 \pm 0,9^{\mathrm{a}}$ & $2,9 \pm 0,8^{\mathrm{a}}$ & $2,5 \pm 0,8^{\mathrm{a}}$ & $2,0 \pm 0,8^{\mathrm{a}}$ & $1,6 \pm 0,7^{\mathrm{a}}$ \\
$\mathbf{0}$ & $2,8 \pm 0,7^{\mathrm{b}}$ & $2,4 \pm 0,8^{\mathrm{b}}$ & $1,8 \pm 0,6^{\mathrm{b}}$ & $1,4 \pm 0,5^{\mathrm{b}}$ & $1,0 \pm 0,5^{\mathrm{b}}$ \\
$\mathbf{1}$ & $0,8 \pm 0,7^{\mathrm{c}}$ & $0,5 \pm 0,4^{\mathrm{c}}$ & $0,2 \pm 0,3^{\mathrm{c}}$ & $0,1 \pm 0,2^{\mathrm{c}}$ & $0,0 \pm 0,1^{\mathrm{c}}$ \\
$\mathbf{3}$ & $0,1 \pm 0,2^{\mathrm{d}}$ & $0,0 \pm 0,1^{\mathrm{d}}$ & $0,0 \pm 0,0^{\mathrm{d}}$ & $0,0 \pm 0,0^{\mathrm{d}}$ & $0,0 \pm 0,0^{\mathrm{c}}$ \\
\hline
\end{tabular}

$a, b, c, d$ - letras diferentes na mesma coluna indicam diferenças significativas $(p<0,05)$ - Teste de MannWhitney
O LPD como diluente apresentou bons resultados de conservação de sêmen a baixas temperaturas, resultado este obtido também por outros autores (Meirelles et al., 1998; Freitas et al., 2011). Aparentemente a inclusão da betaína, em concentrações acima de $1 \mathrm{~g} / 100 \mathrm{~mL}$ influenciou negativamente 0 vigor espermático das amostras, possivelmente por algum fator osmótico relacionado a esta molécula (Trimeche et al., 1999).

Observou-se uma mesma tendência de resultados quando se analisou a motilidade espermática, ou seja, o tratamento controle apresentou os melhores resultados em relação aos demais tratamentos (Tabela 3). A motilidade também sofreu influência negativa da betaína, ou seja, quanto maior a concentração, menores foram os percentuais de células móveis observados.

Há poucos relatos na literatura sobre a inclusão de betaína no diluente para conservação de sêmen na forma líquida, a maioria volta-se para a criopreservação, provavelmente devido a seus mecanismos osmóticos que são desejáveis para o processo (Trimeche et al., 1999). Em desacordo com o presente estudo, onde a betaína não promoveu efeitos positivos sobre a motilidade, o primeiro relato da adição dessa substância ao diluente de conservação de sêmen bovino, mostrou que a betaína manteve a motilidade espermática elevada por 96 horas, quando armazenado a temperaturas abaixo de $20^{\circ} \mathrm{C}$ (Zhang et al., 2001). Além disso, esses autores relataram que em pH próximo de 7,0, pode ser verificada atividade da betaína. Entretanto, em nosso estudo nenhum efeito protetor foi encontrado.

Tabela 3: Motilidade espermática do sêmen suíno conservado em LPD $a 10^{\circ} \mathrm{C}$, com diferentes concentrações de betaína

\begin{tabular}{|c|c|c|c|c|c|}
\hline \multirow{2}{*}{$\begin{array}{c}\text { Tratamentos } \\
\text { (g/100 mL) }\end{array}$} & \multicolumn{5}{|c|}{ Dias de conservação } \\
\hline & Do & D1 & D2 & D3 & D4 \\
\hline 0 & $66,8 \pm 18,8^{a}$ & $62,4 \pm 18,5^{a}$ & $52,8 \pm 19,2^{a}$ & $41,3 \pm 20,3^{a}$ & $31,4 \pm 18,2^{\mathrm{a}}$ \\
\hline 1 & $60,9 \pm 16,2^{b}$ & $53,5 \pm 17,8^{b}$ & $41,7 \pm 17,1^{\mathrm{b}}$ & $31,0 \pm 16,2^{b}$ & $17,5 \pm 13,9^{b}$ \\
\hline 2 & $13,0 \pm 12,6^{c}$ & $8,0 \pm 8,7^{c}$ & $3,5 \pm 6,0^{c}$ & $1,7 \pm 3,6^{c}$ & $0,3 \pm 1,2^{c}$ \\
\hline 3 & $1,1 \pm 4,8^{d}$ & $0,1 \pm 0,7^{d}$ & $0,0 \pm 0,0^{d}$ & $0,0 \pm 0,0^{d}$ & $0,0 \pm 0,0^{c}$ \\
\hline
\end{tabular}

$a, b, c, d$ - letras diferentes na mesma coluna indicam diferenças significativas $(p<0,05)-$ Teste de Mann Whitney

A betaína é um constituinte do plasma seminal nas concentrações entre 04 a 1,5 nmol/L de sêmen. Baixas concentrações dessa substância têm sido relacionadas a diferentes graus de infertilidade em homens (Johnson et al., 2012). Sua molécula desempenha um importante papel na manutenção da função testicular e das células espermáticas e, em particular, sobre a motilidade e concentrações de adenosina trifosfato (ATP). O sêmen de ratos transgênicos machos com menores concentrações de betaína endógena apresentou 55\% menos ATP espermático que em animais normais. É possível que os efeitos iônicos da betaína possam alterar bombas de íons dependentes de ATP, diminuindo assim a utilização de ATP nesses processos, acredita-se também que ela possa alterar a glicólise, necessária para o movimento flagelar do espermatozoide (Johnson et al., 2010) interferindo positivamente sobre a motilidade. 
Entretanto, as concentrações de betaína utilizadas em nosso estudo não favoreceram o aumento da motilidade espermática, provavelmente devido ao aumento da osmolaridade do meio (341, 422 e 510 mOsm, respectivamente em 1g; $2 \mathrm{~g}$ e $3 \mathrm{~g}$ de betaína/ $100 \mathrm{~mL}$ ). Estes valores da depressão osmótica foram superiores aos adotados por Zhang et al. (2001) (275-295 mOsm), que utilizou valores próximos de condições isotônicas (291 mOsmkg-1) observando efeitos positivos da betaína sobre a motilidade espermática.

O possível papel da betaína como um osmólito intracelular, semelhante ao exibido por ela em outras células, foi observado com a adição de $2,5 \%$ de betaína, através de um aumento significativo da motilidade progressiva dos espermatozoides de garanhão, mantendo 95\% da motilidade original (Junnila, 2000). Desta forma, fatores intrínsecos da fisiologia espermática da espécie em questão, podem exercer uma função importante no tocante à ação estimulante ou não da betaína junto às características espermáticas estudadas. Esta possibilidade pôde ser comprovada por Lindeberg et al. (1999) quando, estudando o sêmen equino conservado em diluente com betaína a 4 e $5 \%$, observaram que a motilidade espermática também foi reduzida, verificando um possível efeito deletério. Essa possível toxicidade é provocada por efeitos osmóticos que ocorrem com alta concentração de aminoácido (Trimeche et al., 1999), também observada nesse estudo, com concentrações acima de $1 \%$ de betaína.

Estudos com o sêmen canino congelado, utilizando a betaína como crioprotetor em menor quantidade, apresentaram resultados semelhantes ao deste estudo, onde sua adição a 0,10, 20 e $40 \mathrm{mMol} /$ litro, em comparação com a amostra controle, não melhorou a motilidade do sêmen ou a integridade da membrana plasmática, embora não tenha apresentado um efeito negativo (Peña et al., 1998). Desta forma, para se chegar a um resultado satisfatório com o uso desta substância visando a preservação das características de motilidade espermática, necessário se faz levar-se em consideração a espécie animal estudada, a concentração de betaína utilizada, o meio diluente escolhido e o tipo de conservação (refrigeração ou congelação) do sêmen escolhida.

O percentual de espermatozoides vivos (Tabela 4), obtidos através da análise do esfregaço de sêmen corado em D0 e D4, foi maior $(p<0,05)$ no tratamento controle (LPD) e decresceu com o aumento das concentrações de betaína no diluente, apesar de que em D4 não tenha havido diferenças significativas entre os tratamentos T2-T3 e T3-T4. Os constituintes do leite que fornecem um efeito protetor parecem ser micelas de caseína (as principais proteínas do leite). Tem sido demonstrado que isolados de micelas de caseína do leite protegeram espermatozoides de garanhão (Batellier et al., 1997), de bode (Leboeuf et al., 2003) e de touro (O'shea e Wales, 1966) durante o armazenamento a $4-5^{\circ} \mathrm{C}$. Entretanto, somente as proteínas do leite não foram suficientes para manter a viabilidade espermática diante das diferentes concentrações de betaína deste estudo, sugerindo uma possível interação entre essas moléculas ou que as condições osmóticas impostas tenham influenciado no efeito protetor do leite na manutenção da viabilidade espermática.
Tabela 4: Total de espermatozoides vivos (vitalidade \%) do sêmen suíno, conservado durante quatro dias no diluente LPD a $10^{\circ} \mathrm{C}$ com diferentes concentrações de betaína

\begin{tabular}{ccc}
\hline Tratamentos & \multicolumn{2}{c}{ Dias de conservação } \\
\cline { 2 - 3 }$(\mathbf{g} / \mathbf{1 0 0} \mathbf{~} \mathbf{L})$ & D0 & D4 \\
\hline $\mathbf{0}$ & $65,1 \pm 19,6^{\mathrm{a}}$ & $26,4 \pm 16,1^{\mathrm{a}}$ \\
$\mathbf{1}$ & $41,1 \pm 24,0^{\mathrm{b}}$ & $13,3 \pm 12,6^{\mathrm{b}}$ \\
$\mathbf{2}$ & $21,3 \pm 20,9^{\mathrm{c}}$ & $7,3 \pm 8,1^{\mathrm{bc}}$ \\
$\mathbf{3}$ & $11,9 \pm 14,7^{\mathrm{d}}$ & $4,4 \pm 6,9^{\mathrm{c}}$ \\
\hline
\end{tabular}

$a, b, c, d$ - letras diferentes na mesma coluna indicam diferenças significativas $(p<0,05)$ - Teste Qui-quadrado

Quanto ao total de espermatozoides com acrossoma intacto (Tabela 5) não houve diferenças significativas entre os tratamentos deste estudo $(p>0,05)$. Os aminoácidos são moléculas carregadas, sendo possível uma interação eletrostática com grupos fosfato dos fosfolipídios da membrana plasmática do espermatozoide, formando uma camada sobre superfície da célula e protegendo-a contra o choque térmico (El-Sheshtawy et al., 2008), e desta forma contribuindo para a manutenção da integridade de membrana acrossomal (Fagundes, 2008). Sugere-se que a betaína possa interagir diretamente com os lipídios e proteínas da membrana, alterando o estado de hidratação destas células, protegendo-as, assim, do estresse causado pelo frio (Holt, 2000). Apesar da afirmação destes autores, os resultados da qualidade acrossomal nesse trabalho, não colocaram em evidência esta proteção, uma vez que não apareceram diferenças entre os diferentes tratamentos em relação ao controle. Dois fatores principais podem estar influenciando aqui, as concentrações de betaína e sua influência na osmolaridade do meio bem como o tipo de diluente utilizado, ou seja, o leite em pó desnatado que por si só já apresenta uma boa ação protetora ao espermatozoide do varrão quando conservados em temperaturas baixas $\left(10^{\circ} \mathrm{C}\right)$ (Freitas et al., 2011).

Tabela 5: Total de espermatozoides com acrossoma intacto (\%) do sêmen suíno, conservado durante quatro dias no diluente LPD a $10^{\circ} \mathrm{C}$ com diferentes concentrações de betaína

\begin{tabular}{ccc}
\hline Tratamentos & \multicolumn{2}{c}{ Dias de conservação } \\
\cline { 2 - 3 }$(\mathbf{g} / \mathbf{1 0 0} \mathbf{~} \mathbf{)})$ & $\mathbf{D 0}$ & D4 \\
\hline $\mathbf{0}$ & $95,5 \pm 5,0$ & $93,6 \pm 5,4$ \\
$\mathbf{1}$ & $94,0 \pm 13,5$ & $93,0 \pm 5,9$ \\
$\mathbf{2}$ & $93,9 \pm 13,5$ & $90,8 \pm 7,5$ \\
$\mathbf{3}$ & $93,0 \pm 13,9$ & $90,9 \pm 9,4$ \\
\hline
\end{tabular}

a - letras iguais na mesma coluna, diferenças não significativas $(p>0,05)$ Teste Qui-quadrado 
Analisando-se a característica células vivas com acrossoma intacto (Tabela 6), houve uma mesma tendência observada com a vitalidade (\%). Com o aumento da concentração de betaína houve queda nos percentuais de espermatozoides vivos com acrossoma intacto. Estudo com a adição de pequenas concentrações $(0,5 ; 2 ; 5 \mathrm{mM})$ dos aminoácidos: L-triosina, L-triptofano ou L-fenilalanina resultou em efeitos negativos sobre a viabilidade de espermatozoides de touros. A viabilidade espermática diminuiu com o aumento da concentração desses aminoácidos (Macmillan et al., 1972), resultado semelhante ao que foi observado em nosso estudo. Além disso, espermatozoides mortos liberam a enzima aminoácido oxidase que exerce efeito tóxico sobre a membrana e também sobre a motilidade espermática (Tosic e Walton, 1950). Durante o armazenamento dos espermatozoides, além dessa enzima e outras moléculas prejudiciais ao sêmen, há produção de espécies reativas ao oxigênio que apresentam forte correlação negativa com a vitalidade espermática e integridade de membrana acrossomal (Kumaresan et al., 2009), uma vez que o sêmen suíno apresenta reduzida capacidade em eliminar radicais livres (Tosic e Walton, 1950). Então, com o aumento do tempo de armazenamento, há uma maior produção de radicais livres em detrimento à qualidade espermática. Nesse estudo, o LPD sem adição de betaína, apresentou uma melhor manutenção da qualidade do sêmen, tanto em relação ao percentual de células vivas, como em relação ao de espermatozoides vivos com acrossoma intacto, possivelmente devido à presença de antioxidante em sua composição (vitamina E - Tabela 1). Dessa forma, a perda de qualidade espermática com o incremento da adição de betaína, coloca em evidência seu possível efeito tóxico, o que já foi demonstrado por outros autores utilizando outros aminoácidos (Macmillan et al., 1972; Trimeche et al., 1999).

Tabela 6: Espermatozoides vivos com acrossoma intacto (\%) do sêmen suíno, conservado durante quatro dias no diluente LPD a $10^{\circ} \mathrm{C}$ com diferentes concentrações de betaína

\begin{tabular}{ccc}
\hline \multirow{2}{*}{$\begin{array}{c}\text { Tratamentos } \\
(\mathbf{g} / \mathbf{1 0 0} \mathbf{~} \mathbf{L})\end{array}$} & \multicolumn{2}{c}{ Dias de conservação } \\
\cline { 2 - 3 } $\mathbf{0}$ & $63,0 \pm 19,5^{\mathrm{a}}$ & $\mathrm{D} 4$ \\
\hline $\mathbf{1}$ & $39,7 \pm 22,9^{\mathrm{b}}$ & $25,0 \pm 15,8^{\mathrm{a}}$ \\
$\mathbf{2}$ & $20,4 \pm 19,8^{\mathrm{c}}$ & $12,4 \pm 11,9^{\mathrm{b}}$ \\
$\mathbf{3}$ & $11,3 \pm 14,2^{\mathrm{d}}$ & $6,4 \pm 7,8^{\mathrm{c}}$ \\
\hline
\end{tabular}

$a, b, c, d$ - letras diferentes na mesma coluna indicam diferenças significativas $(p<0,05)$ - Teste Qui-quadrado

A osmolaridade do meio também teve sua influência sobre a qualidade espermática, já que diluentes hipotônicos/hipertônicos afetam negativamente a viabilidade e os percentuais de espermatozoides com acrossoma intacto, particularmente quando a osmolalidade do meio se encontra entre $\geq 500$ mOsmkg-1 ou $\leq 200 m$ Osmkg-1 (Yeste et al., 2010).

O maior percentual de células com membrana funcional (teste hiposmótico - Tabela 7) foi observado em D0 nas amostras do tratamento controle. Ao final da conservação (D4), o tratamento controle ainda manteve-se melhor, entretanto, sem diferença ao tratamento T4 (3 g de betaína/100mL), o qual apresentou uma menor queda do percentual de espermatozoides reativos durante a conservação do sêmen. Mais uma vez, estes resultados podem estar relacionados com as condições osmóticas desfavoráveis (Zou e Yang, 2000), que interferem na morfologia espermática diminuindo a funcionalidade de membrana bem como os percentuais de espermatozoides reativos.

Com declínios de temperatura, há uma redução inevitável na proporção de espermatozoides que mantêm a integridade da membrana e de seus componentes bioquímicos (Johnson et al., 2000), interferindo assim em sua perfeita funcionalidade. Esperava-se, com o uso da betaína, manter um maior número de espermatozoides reativos; entretanto, isto não foi possível com as concentrações determinadas pelo protocolo experimental. A capacidade dos aminoácidos em melhorar a sobrevivência espermática tem sido relacionada com suas propriedades metabólicas, antioxidantes e osmorregulativas (Martins-Bessa et al., 2007); entretanto, uma concentração ideal para o sêmen suíno ainda precisa ser melhor determinada.

Tabela 7: Total de espermatozoides com reativos ao teste hiposmótico (\%) do sêmen suíno, conservado durante quatro dias no diluente LPD a $10^{\circ} \mathrm{C}$ com diferentes concentrações de betaína

\begin{tabular}{ccc}
\hline Tratamentos & \multicolumn{2}{c}{ Dias de conservação } \\
\cline { 2 - 3 }$(\mathbf{g} / \mathbf{1 0 0} \mathbf{~} \mathbf{L})$ & $\mathbf{D 0}$ & $\mathrm{D} 4$ \\
\hline $\mathbf{0}$ & $49,9 \pm 14,6^{\mathrm{a}}$ & $23,9 \pm 10,6^{\mathrm{a}}$ \\
$\mathbf{1}$ & $31,6 \pm 10,2^{\mathrm{b}}$ & $17,7 \pm 8,9^{\mathrm{b}}$ \\
$\mathbf{2}$ & $21,1 \pm 9,9^{\mathrm{c}}$ & $15,5 \pm 8,6^{\mathrm{b}}$ \\
$\mathbf{3}$ & $24,1 \pm 12,2^{\mathrm{c}}$ & $20,2 \pm 9,9^{\mathrm{ab}}$ \\
\hline
\end{tabular}

$a, b, c$ - letras diferentes na mesma coluna indicam diferenças significativas $(p<0,05)$ - Teste Qui-quadrado

Embora os espermatozoides suínos sejam mais sensíveis às mudanças osmóticas no ambiente diluente (Yeste et al., 2010), o estresse osmótico, por si só, não é um fator importante em causar dano à membrana celular dentro de um intervalo de 210 a 1500 mOsm (Du et al., 1994). Isso pode significar que os efeitos dos agentes osmóticos sobre os espermatozoides em grande parte não são somente devido à osmolaridade do meio, mas também oriundos da concentração de íons e do tipo de composto químico adicionado, além de danos causados pelo frio.

É válido ressaltar que no sêmen existem proteínas aglutinantes (PAs) que são prejudiciais aos espermatozoides, principalmente durante o armazenamento. Estas proteínas apresentam-se em baixas concentrações no sêmen suíno (1\%), mas podem danificar a membrana através da remoção de lipídios, tornando-a muito sensível ao armazenamento e a temperaturas baixas (Manjunath, 2012). A caseína e outras proteínas do leite ( $\alpha$-lactalbumina e $\beta$-lactoglobulina) são capazes de interagir com PAs com diferentes graus de afinidade (Lusignan et al., 2011a), dessa forma protegendo o espermatozoide de danos a nível de membrana plasmática. A presença de caseínas em diluente diminui a ligação de PAs aos espermatozoides e impede 
a perda lipídica, mantendo motilidade e viabilidade durante o armazenamento (Bergeron et al., 2007). O efeito protetor do leite é semelhante ao fornecido pela gema de ovo. Entretanto, o mecanismo de proteção conferido pelo leite parece envolver uma interação proteína-proteína em vez da interação proteína-lipídio, como observado com a gema de ovo (Lusignan et al., 2011ab). A perda de funcionalidade da membrana dos espermatozoides reforça os efeitos deletérios das altas concentrações de betaína, inclusive anulando o efeito protetor do leite sobre as células espermáticas.

\section{Referências}

BATELLIER, F.; MAGISTRINI, M.; FAUQUANT, J.; PALMER, E. Effect of milk fractions on survival of equine spermatozoa. Theriogenology, v. 48, n. 3, p. 391-417, 1997.

BERGERON, A.; BRINDLE, Y.; BLONDIN, P.; MANJUNATH, P. Milk caseins decrease the binding of the major bovine seminal plasma proteins to sperm and prevent lipid loss from the sperm membrane during sperm storage. Biology of Reproduction, v. 77, n. 1, p. 120-126, 2007.

DU, J.; TAO, J.; KLEINHANS, F.W.; PETER, A.T.; CRITSER, J.K. Determination of boar spermatozoa water volume and osmotic response. Theriogenology, v. 42, n. 7, p.1183-1191,1994.

EL-SHESHTAWY, R. I.; EL-SISY, G.A.; EL-NATTAT, W.S. Use of selects aminoacids to improve buffalo bull semen cryopreservation. Global Veterinaria, v. 2, n. 4, p. 146-150, 2008.

EKLUND, M.; BAUER, E.; WAMATU, J.; MOSENTHIN, R. Potential nutritional and physiological functions of betaine in livestock. Nutrition Research Reviews, v. 18, n. 1, p. 31-48, 2005.

FAGUNDES, B. Adição de aminoácidos e insulina ao meio crioprotetor seminal de garanhões da raça Mangalarga Marchador. JBCA - Jornal Brasileiro de Ciência Animal, v. 1, n. 1, p. 2008.

FREITAS, E.N.; NUNES, T.G.P.; RODRIGUES, I.C.S.; MARTINS, L.A.; BARROS, T.B.; TONIOLLI, R. Leite em pó desnatado adicio-nado de diferentes concentrações de antioxidante sintético análogo da vitamina E. In: CONBRAVET, 38, 2011. Anais... Florianópolis:SOVERGS. 2011. Acessado em 22/04/2012. Disponível em: <http://www.sovergs.com.br/site/38conbravet/resumos/189.pdf>.

HOLT, W.V. Fundamental aspects of sperm cryobiology: the importance of species and individual differences. Theriogenology, v. 53, n. 1, p. 47-58, 2000.

JOHNSON, L.A; WEITZE, K.F.; FISER, P.; MAXWELL, W.M.C Storage of boar sêmen. Animal Reproduction Science, v. 62, n. 1-3, p.143-172, 2000.

JOHNSON, A.R.; CRACIUNESCU, C. N.; GUO, Z.; TENG, Y. W.; THRESHER, R. J.; BLUSZTAJN, J. K.; Zeisel, S. H. Deletion of murine choline dehydrogenase results in diminished sperm motility. The FASEB Journal, v. 24, n. 8, p. 2752-2761, 2010.

JOHNSON, A. R.; LAO, S.; WANG, T.; GALANKO, J. A.; ZEISEL, S. $\mathrm{H}$. Choline Dehydrogenase Polymorphism rs12676 Is a Functional Variation and Is Associated with Changes in Human Sperm Cell Function. PLoS ONE, v. 7, n. 4, p. 1 - 12, 2012. doi:10.1371/ journal.pone.0036047

JUNNILA, M. Betaine as a lipotropic agent and as na alleviator of osmotic stress. 2000. 70f. Monografia de Graduação (Medicina Veterinária). Faculty of Veterinary Medicine, University of Helsinki, Helsinki, 2000. Disponível em: <http://ethesis.helsinki.fi/julkaisut/ ela/perus/vk/junnila/betainea.pdf> Acesso em: 12/04/2012.

KUMARESAN, A., KADIRVEL, G.; BUJARBARUAH, K. M.; BARDOLOI, R. K.; DAS, A.; KUMAR, S.; NASKAR, S. Preservation of boar semen at $18^{\circ} \mathrm{C}$ induces lipid peroxidation and apoptosis like changes in spermatozoa, Animal Reproduction Science, v. 110, n.1, p. 162-171, 2009.

\section{Conclusões}

A betaína não apresentou um efeito protetor sobre o espermatozoide suíno após sua diluição e conservação em meio à base de leite em pó desnatado à temperatura abaixo dos $17^{\circ} \mathrm{C}$. Concentrações iguais ou acima de $1 \%$ de betaína no diluente influenciaram negativamente a qualidade do sêmen, portanto, não são aplicáveis na sua conservação. Estudos adicionais são necessários a fim de se melhor determinar as concentrações e relações da betaína com o diluente utilizado e a espécie animal em questão.

LEBOEUF, B.; GUILLOUET, P.; BATELLIER, F.; BERNELAS, D.; BONNE, J. L.; FORGERIT, Y.; RENAUD, G.; MAGISTRINI, M. Effect of native phosphocaseinate on the in vitro preservation of fresh semen. Theriogenology, v. 60, n. 5, p. 867-877, 2003.

LINDEBERG, H.; KURTEN, A.; KOSKINEN, E.; KATILA, T. Freezing of stallion semen with addition of glycine betaine. Journal of Veterinary Medicine, Serie A, v. 46, n. 2, p. 87-90, 1999.

LUSIGNAN, M. F.; BERGERON, A.; LAFLEUR, M.; MANJUNATH, $P$. The major proteins of bovine seminal plasma interact with caseins and whey proteins of milk extender. Biology of Reproduction, v. 85, n. 3, p. 457-464, 2011a.

LUSIGNAN, M. F.; MANJUNATH, P.; LAFLEUR, M. Thermodynamics of the interaction between bovine Binder of SPerm BSP1 and lowdensity lipoprotein from hen's egg yolk. Thermochimica Acta, v. 516, n. 1, p. 88-90, 2011b.

MACMILLAN, K. L.; TIKU, J. L.; HART, N. L. Toxic effects of aromatic amino acids on the livability of bull spermatozoa. Australian Journal of Biological Sciences, v. 25, n. 5, p. 1039-45, 1972.

MANJUNATH, P. New insights into the understanding of the mechanism of sperm protection by extender components. Animal Reproduction, v.9, n.4, p.809-815, Oct./Dec. 2012.

MARTINS-BESSA, A., ROCHA, A.,MAYENCO-AGUIRRE, A.. Incorporation of taurine and hypotaurine did not improve the efficiency of the Uppsala Equex II extender for dog semen freezing. Theriogenology, v.68, n. 8, p. 1088-1096, 2007.

MEIRELES, L.S.; MALSCHITSKY, E.; NEVES, A.P.; VIEIRA, M.J.; KELLER, A.; HÖTT, A.K.; MORAES, I.M.A. de; GARBADE, P.; GREGORY, R.M.; MATTOS, R.C. Leite em pó desnatado não inativado e leite desnatado UHT para a preservação e fertilidade do sêmen equino resfriado. Ciência Rural, v. 28, n.3, p. 467-470, 1998.

OCHOA, G.; ORTEGA, R. Evaluacion in vitro e in vivo de semen porcino conservado em diluyentes de larga duracion. Revista Computadorizada de Producción Porcina, v. 15, n. 4, p. 298-306, 2008.

O'SHEA T, WALES RG. Effect of casein, lecithin, glycerol, and storage at $5^{\circ} \mathrm{C}$ on diluted ram and bull semen. Australian Journal of Biological Science, v. 19, n. 5, p. 871-882, 1966.

PEÑA, A.I.; BARRIO, F.; QUINTELA, L.A.; HERRADON, P.G..Proline and Glycine Betaine in a Diluent for Freezing Canine Spermatozoa. Reproduction in Domestic Animal, v. 33, n. 1, p. 5-9, 1998.

SANCHEZ-PARTIDALG, MAXWELLWMC, PALEG LG, SETCHELL BP. Proline and glycine betaine in cryoprotective diluents for ram spermatozoa. Reproduction, Fertility and Development, v.4, n.1, p.113-118, 1992.

SMITAL. J. Effects influencing boar semen. Animal Reproduction Science, v.110, n. 3-4, p.335-346, 2009.

TONIOLLI, R. Pouvoir fecondant des spermatozoides du verrat: amèlioration des conditions de conservation. 1996, $91 \mathrm{f}$. Tese (Doutorado) - Université François Rabelais de Tours - France, 1996. Disponível em: <http://cat.inist.fr/?aModele=afficheN\&cpsi $\mathrm{dt}=182303>$ Acesso em: 10/01/2012. 
TOSIC,J.; WALTON, A. The metabolism of spermatozoa. The formation and eliminationof hydrogen peroxide by spermatozoa and effects on motility and survival. Biochemical Journal, v. 47, n. 2, p. 199-212, 1950.

TRIMECHE, A.; YVON, J.M.; VIDAMENT, M.; PALMER, E.; MAGISTRINI, M. Effects of glutamine, proline, histidine and betaine on post-thaw motility of stallion spermatozoa.Theriogenology, $\mathrm{v}$. 52, n. 1, p. 181-191, 1999.

YESTE, M.; BRIZ, M.; PINART, E.; SANCHO, S.; BUSSALLEU, E.; BONET, S. The osmotic tolerance of boar spermatozoa and its usefulness as sperm quality parameter. Animal Reproduction Science, v. 119, n. 3-4, p. 265-274, 2010.
ZHANG, B.R.; BUHR, M; KROETSCH, T.; LEIBO, S.P. Glycine betaine improves survival of fresh bovine spermatozoa. Reproduction, Fertility and Development, v.13, n. 3, p. 187-192, 2001. Full text doi:10.1071/RD01006.

ZOU, C.; YANG, Z. Evaluation on sperm quality of freshly ejaculated boar semen during in vitro storage under different temperatures. Theriogenology, v. 53, n. 7, p. 1477-1488, 2000. 